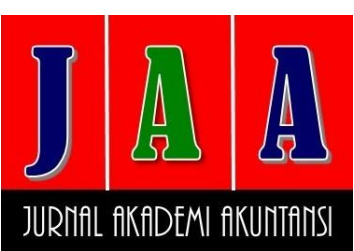

Website:

ejournal.umm.ac.id/index.php/jaa

Afiliasi:

${ }^{1}$ Fakultas Ekonomi dan Bisnis, Universitas Muhammadiyah Malang, Indonesia

*Correspondence:

zubaidah.hasan@gmail.com

DOI: $10.22219 /$ jaa.v3i1.11915

Sitasi:

Zubaidah. S. (2020). Praktik Earning Management Dan Pengaruhnya Terhadap Kompensasi Bonus. Jurnal Akademi Akuntansi, 3(1), 100-117.

Proses Artikel

Diajukan:

11 April 2020

Direviu:

19 April 2020

Direvisi:

25 April 2020

Diterima:

2 Mei 2020

Diterbitkan:

5 Mei 2020

Alamat Kantor:

Jurusan Akuntansi Universitas

Muhammadiyah Malang

Gedung Kuliah Bersama 2

Lantai 3.

Jalan Raya Tlogomas 246,

Malang, Jawa Timur,

Indonesia

P-ISSN: 2715-1964

E-ISSN: 2654-8321
Tipe Artikel: Paper Penelitian

\section{PRAKTIK EARNING MANAGEMENT DAN PENGARUHNYA TERHADAP KOMPENSASI BONUS} Siti Zubaidah ${ }^{1 *}$

\section{ABSTRACT}

The purpose of this study is to identify earning management practices and analyze the effect of earnings management on bonus compensation. The object of research uses the Business Entity and Sharia Business Unit. The selected sample is 34 companies. The Variables used are earnings management and bonus compensation. Data is collected through documentation in the form of financial statements of Business Entities and Sharia Business Units in 2017 and 2018. This study uses a hypothesis test. The test method used is a panel data test using EViews 10 software. The results showed that the practice of earning management in Sharia Business Entities and Business Units is mostly done by income maximization or increasing profit (50\%) and income minimization or decreasing profit (50\%), and there is a significant influence between earning management practices and bonus compensation.

KEYWORDS: Bonus; Compensation; Earnings Management.

\section{ABSTRAK}

Tujuan dari penelitian ini adalah untuk mengidentifikasi praktik manajemen laba dan menganalisis pengaruh manajemen laba terhadap kompensasi bonus. Objek penelitian menggunakan Badan Usaha dan Unit Usaha Syariah. Sampel yang dipilih adalah 34 perusahaan. Variabel yang digunakan adalah manajemen laba dan kompensasi bonus. Data dikumpulkan melalui dokumentasi dalam bentuk laporan keuangan Entitas Bisnis dan Unit Bisnis Syariah pada 2017 dan 2018. Penelitian ini menggunakan uji hipotesis. Metode pengujian yang digunakan adalah uji data panel menggunakan perangkat lunak EViews 10 . Hasil penelitian menunjukkan bahwa praktik manajemen laba pada Entitas Bisnis Syariah dan Unit Bisnis lebih banyak dilakukan dengan maksimalisasi pendapatan atau peningkatan laba (50\%) dan minimalisasi pendapatan atau penurunan laba (50\%), dan terdapat pengaruh yang signifikan antara praktik manajemen laba dan kompensasi bonus.

KATA KUNCI: Bonus; Kompensasi; Manajemen Laba. 


\section{PENDAHULUAN}

Salah satu informasi yang dapat mempengaruhi keputusan investasi adalah earning management. Manajemen seringkali memanfaatkan fleksibilitas yang diperbolehkan oleh Standar akuntansi dalam menyusun laporan keuangan dengan melakukan perubahan metode akuntansi sehingga terlihat penggunaan metodenya tidak konsisten PSAK (no:1 Paragraf 14), hal ini dilakukan dalam rangka menampakkan laba perusahaan menjadi baik di mata investor. Kondisi ini menyebabkan Investor dalam pengambilan keputusan menjadi salah dengan informasi yang disampaikan oleh manajemen. Adanya asimetri informasi antara principle dan agen, menyebabkan peluang bagi agen untuk melakukan earning management. Kondisi tersebut menginspirasi manajemen melakukan earning management. Menurut Scott (2012) earning management merupakan pilihan kebijakan akuntansi oleh manajer untuk mencapai tujuan-tujuan spesifik. Schipper (1989) mendefinisikan manajemen laba sebagai campur tangan dalam proses penyusunan laporan keuangan dengan tujuan memperoleh keuntungan pribadi. Sementara, Badruzaman (2010) mendefinisikan earning management sebagai suatu cara yang ditempuh manajemen dalam mengelola laporan keuangan dengan menggunakan metode akuntansi tertentu dengan tujuan meningkatkan laba perusahaan sehingga kinerja keuangan meningkat. Subramanyam \& Wild (2010) menyatakan bahwa earning management merupakan cara manajer dalam menyusun laporan keuangan dengan melakukan perubahan metode akuntansi dan Belkaoui (2008) menyatakan earning management merupakan potensi penggunaan manajemen accrual dengan tujuan memperoleh keuntungan pribadi.

Praktik earning management dapat dilakukan dengan cara taking a bath, income minimizasion, income maximalization, income smooting. Jika perusahaan melakukan earning management dengan cara income minimizasion berarti perusahaan menurunkan labanya, hal ini dimaksudkan agar labanya tidak nampak terlalu tinggi di mata investor. Jika perusahaan melakukan earning management dengan cara income maximalization berarti perusahaan menaikkan labanya, hal ini dimaksudkan agar labanya nampak tinggi di mata investor.

Kompensasi bonus merupakan balas jasa yang diberikan oleh perusahaan kepada karyawan yang dapat bersifat financial maupun non financial pada periode tetap. Sebagai seorang manajer yang digaji untuk mengelola perusahaan, pasti manajer secara maksimal berusaha untuk mengelola perusahaannya dengan baik dan berusaha meningkatkan kinerja perusahaan, agar di mata pemilik perusahaan kinerja manajer dinilai baik. Biasanya pemilik perusahaan memberikan kompensasi berupa bonus jika manajer dapat meningkatkan laba perusahaan. Dengan adanya kompensasi bonus manajer berusaha mengejarnya dengan cara melakukan earning management dikala perusahaan mengalami penurunan laba atau terjadi kerugian. Manajer selalu ingin dinilai kinerjanya baik atau meningkat di mata investor. Dengan demikian manajer melakukan perubahan-perubahan terhadap metode akuntansi agar nampak laba perusahaan meningkat.

Semakin tinggi kompensasi bonus maka earning management semakin dilakukan oleh manajer. Demikian juga earning management akan mempengaruhi kompensasi bonus. Beberapa penelitian tentang pengaruh earning management terhadap kompensasi bonus adalah Guidry et.al (1999), Elfira (2014) dan Pujiningsih (2011), dalam penelitiannya menunjukkan bahwa

JA ada pengaruh yang signifikan positif antara earning management terhadap kompensasi bonus. Sementara Aprina dan Khairunnisa (2015) tidak ada pengaruh yang signifikan antara earning 3.1 management terhadap kompensasi bonus.

Objek penelitian ini menggunakan Badan Usaha dan Unit Usaha Syariah di Indonesia dari tahun 2017-2018. Seperti diketahui bahwa adanya earning management di perbankan telah 
dibuktikan oleh beberapa peneliti sebelumnya, antara lain (Retnadi, 2008; Setiawati and Na'im, 2000; dan Shen and Chih, 2005), akan tetapi semua penelitian tersebut dilakukan di perbankan konvensional. Oleh karena itu perlu suatu penelitian tentang pengungkapan indikasi earning management terhadap kompensasi bonus di Badan Usaha dan Unit Usaha Syariah.

Berdasarkan uraian latar belakang tersebut, maka permasalahan yang diteliti dirumuskan bagaimana praktik earning manajement pada Badan Usaha dan Unit Usaha Syariah dan pengaruh yang signifikan antara praktik earning manajement dengan kompensasi bonus. Sesuai dengan rumusan masalah tersebut, maka tujuan dari penelitian ini adalah mendiskripsikan praktik earning manajement pada Badan Usaha dan Unit Usaha Syariah, dan menguji pengaruh earning manajement terhadap kompensasi bonus.

\section{TINJAUAN PUSTAKA}

\section{Teori Keagenan}

Adanya asimetri informasi mendorong manajemen demi keuntungan pribadinya tidak mengungkapkan semua informasi yang diterimanya. Teori keagenan (Agency Theory) mengimplikasikan adanya asimetri informasi antara pemilik perusahaan (stakeholder) dan manajer sebagai agen. Adanya asimetri informasi menyebabkan manajemen menggunakan informasi yang diketahuinya untuk menyusun laporan keuangan sesuai dengan kepentingan dirinya yaitu meningkatkan kemakmurannya (Jensen dan Meckling, 1976). Asimetri informasi merupakan suatu keadaan dimana manajer memiliki akses informasi atas prospek perusahaaan yang tidak dimiliki oleh pihak luar perusahaan (Richardson, 1998).

Asimetri informasi pula mendorong manajemen tidak mengungkapkan semua informasi yang diperolehnya kepada penanam modal atau pemilik guna melindungi dirinya atau menutupi tindakan dirinya yang menyebabkan kerugian pemilik. Teori keagenan mendiskripsikan hubungan antara shareholders sebagai principal dan manajemen sebagai agen. Hubungan keagenan merupakan suatu perjanjian atau kontrak dimana satu atau lebih orang (principal) memerintah kepada orang lain (agen) untuk melakukan suatu jasa atas nama principal serta memberi wewenang kepada agen untuk mengambil keputusan terbaik bagi principal. Dalam hubungan tersebut seharusnya agen atau manajemen bertindak sesuai keinginan principal atau shareholders. Tetapi pada praktiknya manajemen banyak bertindak atas kepentingan pribadi dan mengabaikan kepentingan principal demi meningkatkan kemakmuran dirinya. Badruzaman (2010) mendefinisikan earning management sebagai suatu cara yang ditempuh manajemen dalam mengelola laporan keuangan dengan menggunakan metode akuntansi tertentu dengan tujuan meningkatkan laba perusahaan sehingga kinerja keuangan meningkat. Agen melakukan earning manajemen dalam rangka meningkatkan kompensasi bonus dan return saham.

\section{Earning Management}

Menurut Scott (2012) earning management merupakan pilihan kebijakan akuntansi oleh manajer untuk mencapai tujuan-tujuan spesifik. Schipper (1989) mendefinisikan manajemen laba sebagai campur tangan dalam proses penyusunan laporan keuangan dengan tujuan memperoleh keuntungan pribadi. Sementara, Badruzaman (2010) mendefinisikan earning management sebagai suatu cara yang ditempuh manajemen dalam mengelola laporan keuangan dengan menggunakan metode akuntansi tertentu dengan tujuan meningkatkan laba perusahaan sehingga kinerja keuangan meningkat. Subramanyam 
\& Wild (2010) menyatakan bahwa earning management merupakan cara manajer dalam

103 menyusun laporan keuangan dengan melakukan perubahan metode akuntansi dan Belkaoui (2008) menyatakan earning management merupakan potensi penggunaan manajemen accrual dengan tujuan memperoleh keuntungan pribadi.

\section{Praktik Earning Management}

Taking a bath

Taking a Bath adalah pola manajemen laba yang dilakukan dengan cara menjadikan laba perusahaan pada periode berjalan menjadi sangat ekstrim rendah (bahkan rugi) atau sangat ekstrim tinggi di bandingkan dengan laba pada periode sebelumnya dan sesudahnya. Taking a bath terjadi selama periode adanya tekanan organisasi atau pada saat terjadinya reorganisasi, seperti pergantian CEO baru.

\section{Income minimization}

Income minimization adalah pola manajemen yang dilakukan dengan cara menjadikan laba pada laporan keuangan periode berjalan lebih rendah daripada laba sesungguhnya. Income minimization dilakukan pada saat profitabilitas perusahaan sangat tinggi dengan maksud agar tidak mendapat perhatian secara politis. Kebijakan yang diambil dapat berupa penghapusan atas barang modal, aktiva tak berwujud, pembebanan, pengeluaran iklan, pengeluaran $\mathrm{R} \& \mathrm{D}$, dan lainnya.

\section{Income maximization}

Maximisasi laba (Income) adalah pola menejemen laba yang dilkaukan dengan cara menjadikan laba pada laporan keuangan periode berjalan lebih tinggi daripada laba sebelumnya. Income dilakukan dengan cara mempercepat pencatatan pendapatan, menunda biaya, dan memindahkan biaya untuk periode lain. Maximization dilakukan dengan tujuan untuk memperoleh bonus yang lebih tinggi, meningkatkan keuntungan dan untuk menghindari pelanggaran atas kontrak hutang jangka Panjang.

\section{Income smooting}

Income smooting atau perataan laba merupakan salah satu bentuk manajemen laba yang dilakukan dengan cara membuat laba akuntansi relative konsisten (rata) atau smoot dari periode ke periode. Dalam hal ini pihak manajemen dengan sengaja menurunkan atau meningkatkan laba untuk mengurangi gejolak dalam pelaporan laba, sehingga perusahaan terlihat stabil atau tidak berisiko tinggi.

\section{Tujuan Earning Management}

Tujuan dari earning management diantaranya adalah: 1) Meningkatkan kepercayaan pemegang saham terhadap manajer. Earning management berhubungan erat dengan tingkat perolehan laba. Atau prestasi usaha suatu organisasi. Hal ini karena tingkat keuntungan atau

JAA laba dikaitkan dengan prestasi manajemen dan juga besar kecilnya bonus yang akan diterima oleh manajer manajer. 2) Earning management memperbaiki hubungan dengan pihak 3.1 kreditor. Ketika perusahaan tidak mampu menyelesaikan utangnya tepat waktu, perusahaan berusaha menghindarinya dengan membuat kebijakan yang dapat meningkatkan 
pendapatan atau laba. 3) Earning management dapat menarik investor untuk menanamkan investasinya.

\section{Kompensasi Bonus}

Menurut Pujiningsih (2011) kompensasi bonus merupakan balas jasa yang diberikan oleh perusahaan kepada karyawan yang dapat bersifat financial maupun non financial pada periode tetap. Menurut Elfira (2014) kompensasi bonus mencakup hal hal seperti gaji, bonus dan tunjanganatau tambahan penghasilan.

\section{Pengaruh Praktik earning management terhadap kompensasi bonus}

Teori keagenan (Agency Theory) mengimplikasikan adanya asimetri informasi antara pemilik perusahaan (stakeholder) dan manajer sebagai agen. Adanya asimetri informasi menyebabkan manajemen menggunakan informasi yang diketahuinya untuk menyusun laporan keuangan sesuai dengan kepentingan dirinya yaitu meningkatkan kemakmurannya Jensen dan Meckling, 1976). Manajer melakukan perubahan metode akuntansi (earning management) dalam rangka meningkatkan laba, peningkatan laba menyebabkan tingkat kinerja perusahaan semakin tinggi dan kompensasi bonus yang diberikan kepada manajemen semakin tinggi. Beberapa penelitian tentang earning management terhadap kompensasi bonus adalah Guidry et.al (1999), Elfira (2014) dan Pujiningsih (2011), dalam penelitiannya menunjukkan bahwa ada pengaruh yang signifikan positif antara earning management terhadap kompensasi bonus sementara Aprina dan Khairunnisa (2015) tidak ada pengaruh yang signifikan antara earning management dengan kompensasi bonus.

H1: Ada pengarub yang signifikan antara praktik earning Management dengan kompensasi bonus

\section{METODE}

Penelitian ini merupakan penelitian eksplanatori dengan mengambil objek perusahaan Badan Usaha Syariah dan Unit Usaha Syariah. Pemilihan sampel penelitian dilakukan secara purposive sampling, yaitu populasi yang dijadikan sampel merupakan populasi yang memenuhi kriteria tertentu dengan tujuan untuk mendapatkan sampel yang representative sesuai dengan kriteria yang telah ditentukan. Kriteria yang digunakan untuk memilih sampel adalah sebagai berikut: Perusahaan termasuk Badan Usaha Syariah dan Unit Usaha Syariah yang menerbitkan laporan tahunan 2017 dan 2018 dan memiliki data yang lengkap sesuai dengan yang dibutuhkan untuk melakukan penelitian.

Jenis data yang digunakan pada penelitian ini adalah data sekunder, yaitu berupa data laporan keuangan Badan Usaha Syariah dan Unit Usaha Syariah tahun 2017, dan 2018. Sumber data diperoleh dari website masing-masing. Tehnik pengumpulan data pada penelitian ini adalah teknik dokumentasi.

Variabel independen dalam penelitian ini adalah Praktik earning management. Praktik earning manajemen menurut Badruzaman (2010) sebagai suatu cara yang ditempuh manajemen dalam mengelola laporan keuangan dengan menggunakan metode akuntansi tertentu dengan tujuan meningkatkan laba perusahaan sehingga kinerja keuangan meningkat. Praktik earning Management diukur dengan menggunakan proksi discretionary accrual sesuai dengan The Modified Jones Model sebagai berikut:

Menghitung total akrual dengan persamaan berikut:

$\mathbf{T A}_{\mathrm{it}}=\mathbf{N}_{\mathrm{it}}-\mathbf{C F O}_{\mathrm{it}}$ 
Keterangan:

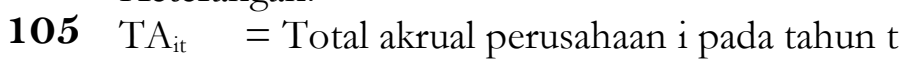

$\mathrm{N}_{\mathrm{it}} \quad=$ Laba bersih perusahaan i pada tahun $\mathrm{t}$

$\mathrm{CFO}_{\text {it }}=$ Arus kas operasi perusahaan i pada tahun $\mathrm{t}$

Menghitung nilai akrual dengan persamaan regresi linear sederhana atau Ordinary Least Square (OLS) dengan persamaan:

$$
\mathrm{TA}_{\mathrm{it}}=\alpha_{0}\left(1 / \mathbf{A}_{\mathrm{it}-1}\right)+\alpha_{1}\left(\Delta \mathrm{REV}_{\mathrm{it}} / \mathbf{A}_{\mathrm{it}-1}\right)+\alpha_{2}\left(\mathbf{P P E}_{\mathrm{it}} / \mathbf{A}_{\mathrm{it}-1}\right)+\mathrm{e}
$$

Keterangan:

$\mathrm{TA}_{\mathrm{it}}=$ Total akrual perusahaan i pada tahun $\mathrm{t}$

$\alpha=$ Fitted coefficient diperoleh dari hasil regresi pada perhitungan total akrual

$\mathrm{A}_{\mathrm{it}-1} \quad=$ Total aset pada periode $\mathrm{t}$

$\Delta \mathrm{REV}_{\mathrm{it}}=$ Pendapan periode $\mathrm{t}$ dikurangi dengan pendapatan periode $\mathrm{t}-1$

$\mathrm{PPE}_{\mathrm{it}}=$ Aktiva tetap (gross property, plant, and

$\mathrm{e} \quad=$ Error term equipment) pada periode $\mathrm{t}$

Menghitung nondiscretionary accruals model (NDA) sebagai berikut:

$\mathrm{NDA}_{\mathrm{it}}=\alpha_{0}\left(1 / \mathrm{A}_{\mathrm{it}-1}\right)+\alpha_{1}\left(\Delta \mathrm{REV}_{\mathrm{it}} / \mathrm{A}_{\mathrm{it}-1}-\Delta \mathrm{REC}_{\mathrm{it}} / \mathrm{A}_{\mathrm{it}-1}\right)+\alpha_{2}\left(\mathbf{P P E}_{\mathrm{it}} / \mathrm{A}_{\mathrm{it}-1}\right)$

Keterangan:

$\mathrm{NDA}_{\mathrm{it}}=$ Nondiscretionary accruals pada tahun $\mathrm{t}$

$\alpha \quad=$ Fitted coefficient diperoleh dari hasil regresi pada perhitungan total akrual

$\mathrm{A}_{\mathrm{it}-1} \quad=$ Total aset pada periode $\mathrm{t}$

$\triangle \mathrm{REV}_{\mathrm{it}}=$ Pendapatan periode $\mathrm{t}$ dikurangi dengan pendapatan periode $\mathrm{t}-1$

$\Delta \mathrm{REC}_{\mathrm{it}}=$ Piutang periode $\mathrm{t}$ dikurangi periode $\mathrm{t}-1$

$\mathrm{PPE}_{\mathrm{it}}=$ Aktiva tetap (gross property, plant, and equipment) pada periode $\mathrm{t}$

\section{Menghitung discretionary accrual:}

$\mathbf{D A}_{\mathrm{it}}=\mathbf{T} \mathbf{A}_{\mathrm{it}}-\mathbf{N D A}_{\mathrm{it}}$

Keterangan:

$\mathrm{DA}_{\mathrm{it}}=$ Discretionary accruals perusahaan $\mathrm{i}$ pada periode $\mathrm{t}$

$\mathrm{TA}_{\mathrm{it}}=$ Total akrual perusahaan i pada tahun $\mathrm{t}$

$\mathrm{NDA}_{\mathrm{it}}=$ Nondiscretionary accruals pada tahun $\mathrm{t}$

Praktek earning manajemen dapat ditentukan dari nilai $\mathbf{D} \mathbf{A}_{\mathrm{it}}$,

Jika $\mathbf{D A}_{\mathbf{i t}}>1$ berarti Income minimization

Jika $\mathbf{D A}_{\mathrm{it}}<1$ berarti Income maximization

Jika $\mathbf{D A}_{\mathrm{it}}=1$ berarti Income Smooting

3.1 Variabel dependen dalam penelitian ini adalah kompensasi bonus. Kompensasi bonus merupakan balas jasa yang diberikan oleh perusahaan kepada karyawan yang dapat bersifat financial maupun non financial pada periode tetap. Kompensasi bonus diukur dengan jumlah bonus yang diberikan 


\section{Analisis Data}

Penelitian ini menggunakan uji hipotesis. Metode pengujian yang digunakan adalah uji data panel dengan menggunakan software EViews 10. Tahapan analisis data adalah mengumpulkan data sekunder berupa laporan keuangan dan tahunan perusahaan pertambangan sesuai kategori purposive sampling, melakukan tabulasi data penelitian, melakukan perhitungan kepada masing-masing variabel yang akan diuji, dan uji data melalui model regresi data panel.

Terdapat keuntungan dalam menggunakan data panel (Gurajati, 2006), yaitu dengan kombinasi time series dan cross section, data panel memberikan data yang lebih informatif, lebih variatif, mengurangi kolinieritas, derajat kebebasan dan efisiensi yang lebih besar. Selanjutnya adalah dengan mempelajari bentuk cross section secara berulang-ulang dari observasi, disimpulkan bahwa data panel lebih baik untuk mempelajari dinamika perubahan. Data panel dapat berinteraksi lebih baik dan mengukur berbagai efek yang tidak dapat diobservasi dalam cross section murni maupun data time series murni. Data panel memungkinkan mempelajari model perilaku yang lebih rumit. Data panel dapat mengurangi bias yang yang terjadi jika dilakukan uji secara agregat. Data panel dapat memperkaya analisis empiris dengan berbagai cara yang mungkin tidak terjadi jika menggunakan crosssection maupun time series. Data panel tidak membutuhkan uji ekonometri. Uji ekonometri dilakukan untuk melihat apakah spesifikasi model yang digunakan sudah memenuhi asumsi klasik atau tidak. Terdapat tiga jenis model data panel yang tersedia yang nantinya akan dipilih salah satu model yang terbaik untuk melakukan uji hipotesis.

Ketiga model uji hipotesis adalah sebagai berikut:

\section{Common-Effect Model}

Model ini memperlakukan semua individu seakan-akan sama, atau tidak membeda-bedakan karakteristik antar individu yang terlihat dari nilai intersepnya yang sama untuk semua individu. Secara sederhana model ini akan menggabungkan observasi waktu dan individu tanpa memperhatikan perbedaan karakteristik individu, serta menggunakan regresi OLS (ordinary least square) seperti regresi pada umumnya. Secara umum, bentuk model linear (yang disebut regression pooling) yang dapat digunakan untuk memodelkan data panel adalah:

$$
\mathrm{yti}=\alpha+\chi \mathrm{ti} \beta \mathrm{ti}+\varepsilon \mathrm{ti}
$$

Dimana :

Yti adalah variabel terikat individu ke-i periode ke-t.

$\alpha$ adalah intersep gabungan.

$\beta$ adalah koefisien regresi atau slope.

$\chi$ adalah variabel independent atau regressor dari unit ke-i dan diamati dari periode ke-t.

$\varepsilon$ adalah komponen error individu ke-i periode ke-t.

i adalah individu (cross section).

$\mathrm{T}$ adalah waktu. 


\section{Fixed-Effect Model}

Salah satu model estimasi yang bisa digunakan pada model regresi data panel adalah fixed effect model atau sering disebut juga sebagai least square dummy variabel (LSDV). Disebut fixed effect model karena setiap individu dalam model memiliki intersep yang tidak berubah sepanjang waktu meskipun intersep antar individu berbeda. Berikut model regresi data panel pada model fixed-effect adalah:

$$
\text { Yti }=\alpha+\alpha 1+\chi \mathrm{ti} \beta \mathrm{ti}+\varepsilon \mathrm{ti}
$$

Untuk mengestimasi model ini, dapat menggunakan regresi dengan variabel dummy dimana setiap individu akan menjadi variabel dummy. Dengan menjadikan setiap individu menjadi variabel dummy, maka akan ada satu yang menjadi basis sebagai pembanding untuk menghindari perangkap variabel dummy.

\section{Random-Effect Model}

Model ini berbeda dengan model efek tetap atau fixed effect model, walaupun keduanya mampu mengatasi masalah adanya heterogenitas antar individu. Akan tetapi random effect model mengatasi msalah heterogenitas individu pada error. Hal ini untuk menjawab permasalahan yang ada pada fixed effect model jika terdapat individu yang banyak akan membutuhkan variabel dummy yang lebih banyak sehingga dapat mengurangi efisiensi model. Modelnya dituliskan sebagai berikut:

$$
\begin{aligned}
& \text { yti }=\alpha+\alpha 1+\chi \text { ti }_{\beta} \text { ti }+\varepsilon t i \\
& \text { eti }=u 1+v t+w t i
\end{aligned}
$$

u1 adalah komponen error cross section.

Vt adalah komponen error time series.

Wti adalah komponen error gabungan.

Model estimasi yang digunakan dalam random effect model adalah generalized least square (GLS). Asumsi terpenting pada random effect model adalah tidak terdapat korelasi atau hubungan antar error individu dengan variabel penjelas (independent) dalam model, sehingga tidak diperlukan uji asumsi klasik pada model. Inilah yang membedakan random effect model dengan fixed effect model (Gurajati, 2006).

\section{Pemilihan Model Regresi Data Panel}

Pemilihan model pada regresi data panel diawali dengan menetapkan model awal terlebih dahulu. Penetapan model awal didasarkan pada bagaimana individu (cross section) diambil. Jika individu diambil dengan dipilih atau ditentukan oleh peneliti, maka model awalanya adalah model efek tetap (fixed effect model). Bila individu diambil secara acak, maka model yang digunakan adalah model acar tetap (random efek model) (Baltagi, 2008). Dalam penelitian ini, kategori individu (cross section) dipilih melalui katogori peneliti, sehinggal model awal yang ditetapkan adalah fixed effect model. Jika model awal yang terpilih adalah model efek tetap, maka akan dilakukan uji chow untuk memilih antara model koefisien tetap (pooled regression/common effect model) dengan fixed effect model. Jika model yang terpilih adalah fixed effect model, maka dilakukan pengujian untuk memilih antara fixed effect model dengan random efek

JAA model melalui uji hausman. Ketika model yang terpilih adalah fixed effect model, maka akan dilakukan pemeriksaan asumsi-asumsi klasik yang ada pada regresi panel dengan metode 3.1 estimasi ordinary least square. Jika model yang terpilih adalah random effect model, maka tidak perlu melakukan uji asumsi klasik karena model estimasi yang digunakan adalah generalized least square (GLS). 
Asumsi terpenting dalam model ini adalah tidak terdapat korelasi atau hubungan antar error dari masing-masing individu dengan variabel independent dalam model (Gurajati, 2006). Kemudian setelah menentukan model yang digunakan, baru dilakukan uji model (goodness of fit test) seperti uji simultan (uji F) dan parsial (uji t).

\section{Melakukan Uji Chow Untuk Menentukan Common Effect Model atau Fixed Effect Model}

Uji ini digunakan untuk memilih model regresi data panel yang terbaik diantara common effect model atau fixed effect model. Hipotesis awal dari uji adalah fixed effect model. Maka prosedur pengujianya adalah sebagai berikut (Baltagi, 2008):

H0 : common effect model

H1 : fixed effect model

Statistik ui yang digunakan adalah uji F, dimana:

F hitung $=($ RRSS - URRS $) /(\mathrm{N}-1)$

URSS/NT-N-K

Keterangan :

$\mathrm{N}=$ jumlah individu (cross section)

$\mathrm{T}=$ jumlah periode waktu (time series)

$\mathrm{K}=$ jumlah variabel penjelas (independen)

RRSS $=$ restricted residual sums of squares yang berasal dari model koefisien tetap.

URSS = unrestricted residual sums of squares yang berasal dari model efek tetap.

Jika F hitung > F tabel, maka hipotesis nol (common effect model) akan ditolak. Maka model yang dipilih adalah fixed effect model. Menurut (Baltagi, 2008), cara lain untuk melihat hasil uji chow adalah dengan melihat nilai probabilitas chi square. Jika nilai probabilitas chi square $>$ taraf signifikansi, maka tolak $\mathrm{H} 1$ atau model yang digunakan adalah model commoneffect. Sebaliknya jika nilai probabilitas chi square $<$ taraf signifikansi, maka terima $\mathrm{H} 1$ atau model yang digunakan adalah model fixed effect.

\section{Melakukan Uji Hausmann Untuk Menentukan Fixed Effect Model Atau Random Effect Model}

Uji ini bertujuan untuk memilih model yang terbaik antara metode fixed effect model atau random effect model. Uji ini menguji apakah terdapat hubungan antara error pada model dengan salah satu varibel independen dalam model. Prosedur untuk pengujian Hausmann adalah:

$\mathrm{H} 0=$ model Random-Effect

H1 = model Fixed-Effect

Jika nilai probabilitas uji hausmann $<$ taraf signifikansi, maka H1 diterima atau model yang tepat adalah model fixed effect. Begitupun sebaliknya, jika nilai probabilias uji hausmann $>$ taraf signifikansi, maka tolak H1atau model yang digunakan adalah model random effect (Baltagi,2008).

\section{Melakukan Pengujian Hipotesis}

Setelah diperoleh model terbaik, selanjutnya dilakukan pengujian hipotesis dengan 
dilakukan dengan menggunakan uji t dengan tujuan untuk melihat seberapa besar pengaruh masing-masing variabel independen secara parsial dalam menerangkan variabel dependent. Uji signifikansi model secara keseluruhan dapat dilakukan dengan uji F. Uji F bertujuan untuk melihat ada tidaknya pengaruh bersama-sama antar variabel independent terhadap variabel dependent. Sedangkan koefisien determinasi $\left(\mathrm{R}_{2}\right)$ adalah salah satu bentuk nilai statistik yang dapat digunakan untuk mengetahui apakah ada hubungan pengaruh antara dua variabel. Koefisien determinasi $\left(\mathrm{R}_{2}\right)$ pada intinya mengukur seberapa jauh kemampuan model dalam menerangkan variasi variabel terikat.

\section{Pengujian Hipotesis}

\section{Uji Parsial (parsial test)}

Uji statistik t pada dasarnya menunjukan seberapa jauh pengaruh satu variabel penjelas secara individual dalam menerangkan variasi variabel terikat (Kuncoro, 2003). Uji-t digunakan untuk menguji koefisien regresi secara individu. Pengujian dilakukan terhadap koefisien regresi populasi, apakah sama dengan nol, yang berarti variabel bebas tidak mempunyai pengaruh signifikan terhadap variabel terikat, atau tidak sama dengan nol, yang berarti variabel bebas mempunyai pengaruh signifikan terhadap variabel terikat.

\section{Uji Serentak (Overall test)}

Uji yang dilakukan untuk mengetahui pengaruh secara bersama-sama variabel bebas terhadap variabel terikat, uji ini dapat dilakukan untuk menguji kecocoan model (goodness of fit). Nilai $\mathrm{F}$ dari hasil perhitungan ini dibandingkan dengan Ftabel yang diperoleh melalui signifikan level 5\% atau dengan degree freedom $=\mathrm{n}-\mathrm{k}-1$.

Kesimpulan dari hasil uji ini adalah sebagai berikut:

Ho ditolak, jika nilai Fhitung $>$ F tabel

Ho diterima, jika nilai Fhitung $<$ Ftabel

\section{Koefisien Determinasi}

Koefisien Determinasi $\left(\mathrm{R}_{2}\right)$ adalah salah satu bentuk nilai statistik yang dapat digunakan untuk mengetahui apakah ada hubungan pengaruh antara dua variabel. Koefisien Determinasi $\left(R_{2}\right)$ pada intinya mengukur seberapa jauh kemampuan model dalam menerangkan variasi variabel terikat. Nilai koefisien determinasi $\left(\mathrm{R}_{2}\right)$ menunjukkan presentase variasi nilai variabel terikat yang dapat dijelaskan oleh persamaan regresi yang dihasilkan. Bila nilai $\mathrm{R}_{2}$ semakin mendekati 1 , berarti semakin tepat suatu garis regresi digunakan sebagai pendekatan. Sebaliknya semakin kecil nilai berarti semakin tidak tepat garis regresi tersebut mewakili data dari hasil observasi.

Jika nilai $\mathrm{R}_{2}$ sama dengan 1, maka pendekatan tersebut terdapat kecocokan sempurna dan jika nilai $\mathrm{R}_{2}$ sama dengan 0, maka tidak ada kecocokan pendekatan. Selain itu, koefisien determinasi $\left(R_{2}\right)$ ini juga untuk mengukur besarnya kontribusi (persentase) dari jumlah variabel terikat yang diterangkan oleh regresi atau untuk mengukur besarnya sumbangan dari variabel bebas terhadap naik turunya nilai variabel terikat. Sedangkan koefisien korelasi

JAA dapat dihitung dengan cara menarik akar dari koefisien determinasi. Koefisien korelasi ini digunakan untuk mengetahui keeratan hubungan antara dua variabel dan mengetahui arah

3.1 hubungan antara dua variabel, dimana batas-batasnya ditentukan oleh $-1 \leq \mathrm{r} \leq 1$. Bila $\mathrm{r}=0$ atau mendekati 0, maka hubungan antara kedua variabel sangat lemah atau tidak ada hubungan sama sekali. 
Bila $\mathrm{r}=+1$ atau mendekati 1 , maka korelasi antara variabel dikatakan positif dan sangat kuat. Tanda positif (+) menyatakan bahwa korelasi antara dua variabel adalah searah, artinya kenaikan nilai $\mathrm{X}$ terjadi bersama-sama dengan kenaikan nilai $\mathrm{Y}$, sedangkan bila nilai $\mathrm{r}=-1$ atau mendekati -1 , maka korelasi sangat kuat dan negatif. Tanda negatif (-) menyatakan bahwa kenaikan nilai X terjadi bersama-sama dengan penurunan nilai.

\section{HASIL DAN PEMBAHASAN}

Objek penelitian dalam penelitian ini adalah Badan Usaha dan Unit Usaha Syariah selama periode tahun 2017-2018. Penentuan sampel penelitian dilakukan dengan metode purposive sampling yakni berdasarkan kriteria-kriteria yang telah ditentukan dalam penelitian ini. Terdapat 34 Badan Usaha dan Unit Usaha Syariah selama periode penelitian.

Jumlah sampel yang dikumpulkan tersebut telah memenuhi kriteria yang di perlukan dalam penelitian. Adapun data perusahaan yang telah diseleksi sesuai dengan kriteria yang harus dipenuhi dalam penentuan sampel penelitian ini adalah sebagai berikut:

Tabel 1.

Proses

\begin{tabular}{cc}
\hline Kriteria Pemilihan Sampel & Jumlah \\
\hline Badan usaha dan unit usaha syariah & 34 \\
Badan usaha dan unit usaha syariah yang memiliki data lengkap & 34 \\
Jumlah Sampel & $\mathbf{3 4}$
\end{tabular}

Pemilihan

Sampel

Jumlah Sampel

\begin{tabular}{ccl}
\hline No. & \multicolumn{1}{c}{ Nama Perusahaan } \\
\hline & 1 & PT BANK ACEH SYARIAH \\
& 2 & PT BPD NTB SYARIAH \\
3 & PT BANK MUAMALAT \\
& 4 & PT VICTORIA SYARIAH \\
& 5 & PT BRI SYARIAH \\
& 6 & PT BJB SYARIAH \\
& 7 & PT BANK BNI SYARIAH \\
& 8 & PT BANK SYARIAH MANDIRI \\
2. & 9 & PT BANK MEGA SYARIAH \\
ma & 10 & PT BANK PANIN DUBAI SYARIAH \\
an & 11 & PT BANK SYARIAH BUKOPIN \\
m & 12 & PT BCA SYARIAH \\
ah & 13 & PT BANK TPN SYARIAH \\
\cline { 2 - 3 } & 14 & PT MAYBANK SYARIAH \\
\hline
\end{tabular}

Sumber : data diolah 


\begin{tabular}{cl}
\hline No. & \multicolumn{1}{c}{ Nama Perusahaan } \\
\hline 1 & PT Bank Danamon Indonesia, Tbk \\
2 & PT Bank Permata, Tbk \\
3 & PT Bank Maybank Indonesia, Tbk \\
4 & PT Bank CIMB Niaga, Tbk \\
5 & PT Bank OCBC NISP, Tbk \\
6 & PT Bank Sinarmas \\
7 & PT Bank Tabungan Negara (Persero) \\
8 & PT BPD DKI \\
9 & PT BPD Daerah Istimewa Yogyakarta \\
10 & PT BPD Jawa Tengah \\
11 & PT BPD Jawa Timur, TBk \\
12 & PT BPD Sumatera Utara \\
13 & PT BPD Jambi \\
14 & PT BPD Sumatera Barat \\
15 & PT BPD Riau dan Kepulauan Riau \\
16 & PT BPD Sumatera Selatan dan Bangka Belitung \\
17 & PT BPD Kalimantan Selatan \\
18 & PT BPD Kalimantan Barat \\
19 & PT BPD Kalimantan Timur \\
20 & PT BPD Sulawesi Selatan dan Sulawesi Barat
\end{tabular}

Tabel 3.

Nama

Perusahaan Sampel

Unit Usaha

Syariah

Sumber : data diolah

\section{Penyajian Data}

\begin{tabular}{|c|c|c|c|}
\hline No. & Nama Perusahaan & & $\begin{array}{l}\text { ata Bonus (Y) } \\
2018\end{array}$ \\
\hline 1 & PT BANK ACEH SYARIAH & $\mathrm{Rp}$ & $592,809,311,090$ \\
\hline 2 & PT BPD NTB SYARIAH & $\mathrm{Rp}$ & $29,672,521,131$ \\
\hline 3 & PT BANK MUAMALAT & $\mathrm{Rp}$ & $845,632,021,000$ \\
\hline 4 & PT VICTORIA SYARIAH & $\mathrm{Rp}$ & $30,695,088,533$ \\
\hline 5 & PT BRI SYARIAH & $\mathrm{Rp}$ & $510,828,000,000$ \\
\hline 6 & PT BJB SYARIAH & $\mathrm{Rp}$ & $177,048,252,000$ \\
\hline 7 & PT BANK BNI SYARIAH & $\mathrm{Rp}$ & $937,794,000,000$ \\
\hline 8 & PT BANK SYARIAH MANDIRI & $\mathrm{Rp}$ & $1,805,975,000,000$ \\
\hline 9 & PT BANK MEGA SYARIAH & $\mathrm{Rp}$ & $147,619,489,000$ \\
\hline 10 & $\begin{array}{l}\text { PT BANK PANIN DUBAI } \\
\text { SYARIAH }\end{array}$ & $\mathrm{Rp}$ & $101,872,152,000$ \\
\hline 11 & PT BANK SYARIAH BUKOPIN & $\mathrm{Rp}$ & $80,902,521,553$ \\
\hline 12 & PT BCA SYARIAH & $\mathrm{Rp}$ & $92,148,860,031$ \\
\hline 13 & PT BANK TPN SYARIAH & $\mathrm{Rp}$ & $899,148,000,000$ \\
\hline 14 & PT MAYBANK SYARIAH & $\mathrm{Rp}$ & $34,278,000,000$ \\
\hline
\end{tabular}

Tabel 4.

Data

Kompensasi Bonus

Bank Umum Syariah 


\begin{tabular}{|c|c|c|c|}
\hline No. & Nama Perusahaan & & $\begin{array}{c}\text { Data Bonus (Y) } \\
2018\end{array}$ \\
\hline 1 & PT Bank Danamon Indonesia, Tbk & $\mathrm{Rp}$ & $4,966,120,000,000$ \\
\hline 2 & PT Bank Permata, Tbk & $\mathrm{Rp}$ & $2,380,462,000,000$ \\
\hline 3 & PT Bank Maybank Indonesia, Tbk & $\mathrm{Rp}$ & $2,460,991,000,000$ \\
\hline 4 & PT Bank CIMB Niaga, Tbk & $\mathrm{Rp}$ & $4,001,791,000,000$ \\
\hline 5 & PT Bank OCBC NISP, Tbk & $\mathrm{Rp}$ & $2,152,080,000,000$ \\
\hline 6 & PT Bank Sinarmas & $\mathrm{Rp}$ & $633,054,000,000$ \\
\hline 7 & PT Bank Tabungan Negara (Persero) & $\mathrm{Rp}$ & $2,876,562,000,000$ \\
\hline 8 & PT BPD DKI & $\mathrm{Rp}$ & $836,719,000,000$ \\
\hline 9 & PT BPD Daerah Istimewa Yogyakarta & $\mathrm{Rp}$ & $194,639,238,684$ \\
\hline 10 & PT BPD Jawa Tengah & $\mathrm{Rp}$ & $1,213,437,868,000$ \\
\hline 11 & PT BPD Jawa Timur, TBk & $\mathrm{Rp}$ & $1,411,911,000,000$ \\
\hline 12 & PT BPD Sumatera Utara & $\mathrm{Rp}$ & $765,288,612,395$ \\
\hline 13 & PT BPD Jambi & $\mathrm{Rp}$ & $171,864,105,672$ \\
\hline 14 & PT BPD Sumatera Barat & $\mathrm{Rp}$ & $684,673,011,536$ \\
\hline 15 & PT BPD Riau dan Kepulauan Riau & $\mathrm{Rp}$ & $32,227,993,562$ \\
\hline 16 & PT BPD Sumatera Selatan dan Bangka Belitung & $\mathrm{Rp}$ & $437,875,980,000$ \\
\hline 17 & PT BPD Kalimantan Selatan & $\mathrm{Rp}$ & $267,337,228,772$ \\
\hline 18 & PT BPD Kalimantan Barat & $\mathrm{Rp}$ & $419,909,456,000$ \\
\hline 19 & PT BPD Kalimantan Timur & $\mathrm{Rp}$ & $437,375,000,000$ \\
\hline 20 & PT BPD Sulawesi Selatan dan Sulawesi Barat & $\mathrm{Rp}$ & $434,007,307,623$ \\
\hline
\end{tabular}

Sumber : data diolah

\begin{tabular}{|c|c|c|}
\hline No. & Nama Perusahaan & $\begin{array}{c}\text { Earning Management (X) } \\
2017 \\
\end{array}$ \\
\hline 1 & PT BANK ACEH SYARIAH & 0.570478 \\
\hline 2 & PT BPD NTB SYARIAH & 0.021561 \\
\hline 3 & PT BANK MUAMALAT & $-0,02687$ \\
\hline 4 & PT VICTORIA SYARIAH & 0.015545 \\
\hline 5 & PT BRI SYARIAH & $-0,00842$ \\
\hline 6 & PT BJB SYARIAH & 0.012607 \\
\hline 7 & PT BANK BNI SYARIAH & $-0,00458$ \\
\hline 8 & PT BANK SYARIAH MANDIRI & 0,038554 \\
\hline 9 & PT BANK MEGA SYARIAH & -0.00403 \\
\hline 10 & PT BANK PANIN DUBAI SYARIAH & $-0,18534$ \\
\hline 11 & PT BANK SYARIAH BUKOPIN & -0.00304 \\
\hline 12 & PT BCA SYARIAH & 0,04365 \\
\hline 13 & PT BANK TPN SYARIAH & 0,04524 \\
\hline 14 & PT MAYBANK SYARIAH & $-0,00515$ \\
\hline
\end{tabular}

Sumber : data diolah 


\section{Analisis Data}

Analisis Statistik Deskriptif

\begin{tabular}{lrrr}
\hline & LOG_Y_BONUS & C & X_EARNING_MANAGEMENT \\
\hline Mean & 11.64473 & 1 & -0.14281 \\
Median & 11.74059 & 1 & 0.007569 \\
Maximum & 12.69602 & 1 & 0.570478 \\
Minimum & 10.47235 & 1 & -6.0032 \\
Std. Dev. & 0.626348 & 0 & 1.047358 \\
\hline
\end{tabular}

Tabel 7.

Hasil Analisis Statistik

Deskriptif

Sumber : data diolah

\section{Kompensasi Bonus}

Berdasarkan tabel perusahaan yang memiliki kompensasi terendah yaitu PT BPD NTB Syariah 10.47235. Sedangkan kompensasi bonus tertinggi yaitu pada PT Bank Danamon Indonesia 12.69602. Sedangkan nilai rata-rata bonus adalah 11.64473 dengan standart deviasi sebesar 0.626348 .

\section{Earning Management}

Berdasarkan tabel perusahaan yang memiliki Earning Management terendah yaitu PT BPD Riau dan Kpulaua Riau -6.0032. Sedangkan nilai pengungkapan tertinggi yaitu pada PT Bank BNI Syariah 10.570478. sedangkan nilai rata-rata Earning Management adalah -0.14281 dengan standart deviasi sebesar 1.047358.

\section{Uji Asumsi Klasik}

\section{Uji Normalitas}

\begin{tabular}{|lr|}
\hline \multicolumn{2}{|l}{ Series: Residuals } \\
Sample 1 34 \\
\multicolumn{2}{|l}{ Observations 34} \\
Mean & $2.14 \mathrm{e}-15$ \\
Median & 0.028137 \\
Maximum & 1.026622 \\
Minimum & -1.204787 \\
Std. Dev. & 0.591311 \\
Skewness & -0.374965 \\
Kurtosis & 2.509716 \\
& \\
Jarque-Bera & 1.137264 \\
Probability & 0.566300 \\
\hline
\end{tabular}

Sumber : data diolah

Hasil uji normalitas residual di atas adalah: nilai jarque bera sebesar 1.137264 dengan $\mathrm{p}$ JAA value sebesar 0,566300 dimana $>0,05$ sehingga terima $\mathrm{H} 1$ atau yang berarti residual berdistribusi normal. 


\section{Uji Multikolinearitas}

Sample: 134

Included observations: 34

\begin{tabular}{|c|c|c|c|c|}
\hline Tabel 8. & Variable & Variance & VIF & VIF \\
\hline Iltil & $\mathrm{C}$ & 98 & 1.0 & $\mathrm{~N}$ \\
\hline & X_EARNING_MANAGEMENT & 0.009961 & 1.019155 & 1.000000 \\
\hline
\end{tabular}

Sumber : data diolah

Di atas menunjukkan bahwa nilai Centered VIF X1 adalah 1,000000 dimana nilai tersebut kurang dari 10, maka dapat dinyatakan bahwa tidak terdapat masalah multikolinearitas dalam model prediksi.

\section{Uji Heteroskedasitas}

Heteroskedasticity Test: Breusch-Pagan-Godfrey

\begin{tabular}{llll}
\hline \hline F-statistic & 0.427500 & Prob. F(1,32) & 0.5179 \\
Obs*R-squared & 0.448230 & Prob. Chi-Square(1) & 0.5032 \\
Scaled explained SS & 0.299715 & Prob. Chi-Square(1) & 0.5841 \\
\hline \hline
\end{tabular}

Test Equation:

Dependent Variable: RESID^2

Method: Least Squares

Date: 12/20/19 Time: 13:11

Sample: 134

Included observations: 34

\begin{tabular}{lrlll}
\hline \hline \multicolumn{1}{c}{ Variable } & Coefficient & Std. Error & t-Statistic & Prob. \\
\hline \multicolumn{1}{c}{ C } & 0.345991 & 0.073923 & 4.680444 & 0.0001 \\
X_EARNING_MANAGEMENT & 0.046400 & 0.070965 & 0.653835 & 0.5179 \\
\hline \hline R-squared & 0.013183 & Mean dependent var & 0.339365 \\
Adjusted R-squared & -0.017655 & S.D. dependent var & 0.423251 \\
S.E. of regression & 0.426970 & Akaike info criterion & 1.192818 \\
Sum squared resid & 5.833718 & Schwarz criterion & 1.282604 \\
Log likelihood & -18.27791 & Hannan-Quinn criter. & 1.223438 \\
F-statistic & 0.427500 & Durbin-Watson stat & 1.355767 \\
Prob(F-statistic) & 0.517890 & & & \\
\hline \hline
\end{tabular}

Sumber : data diolah

Output tersebut di atas, dimana nilai $\mathrm{p}$ value yang ditunjukkan dengan nilai Prob. chi square(2) pada Obs*R-Squared yaitu sebesar 0,5032. Oleh karena nilai $\mathrm{p}$ value $0,5032>$ 0,05 maka terima $\mathrm{H} 0$ atau ang berarti model regresi bersifat homoskedastisitas atau dengan

Tabel 9. Sum squared resid

Hasil Uji Log likelihood

Heterosked F-statistic

asitas

kata lain tidak ada masalah asumsi non heteroskedastisitas. 


\section{Uji Hipotesis}

Dependent Variable: LOG_Y_BONUS

\begin{tabular}{|c|c|c|c|}
\hline \multicolumn{4}{|l|}{ Method: Least Squares } \\
\hline Date: $12 / 20 / 19$ Time: $12: 57$ & & & \\
\hline \multicolumn{4}{|l|}{ Sample: 134} \\
\hline \multicolumn{4}{|l|}{ Included observations: 34} \\
\hline Variable & Coefficient & Std. Error & Prob. \\
\hline $\mathrm{C}$ & 11.67289 & 0.103963 & 0.0000 \\
\hline X_EARNING_MANAGEMENT & 0.197209 & 0.099804 & 0.0568 \\
\hline R-squared & 0.108746 & Mean dependent var & 11.64473 \\
\hline Adjusted R-squared & 0.080894 & S.D. dependent var & 0.626348 \\
\hline S.E. of regression & 0.600479 & Akaike info criterion & 1.874846 \\
\hline Sum squared resid & 11.53842 & Schwarz criterion & 1.964632 \\
\hline Log likelihood & -29.87238 & Hannan-Quinn criter. & 1.905465 \\
\hline F-statistic & 3.904462 & Durbin-Watson stat & 1.477936 \\
\hline Prob(F-statistic) & 0.056833 & & \\
\hline
\end{tabular}

Tabel 10.

\section{Koefisien Determinasi}

Koefisien determinasi $\left(\mathrm{R}^{2}\right)$ dapat menjelaskan proporsi variabel dependen yang dapat dijelaskan oleh variabel independen secara bersamaan. Nilai koefisien determinasi berkisar antara $0 \leqq \mathrm{R}^{2}$ semakin mendekati 1 maka pengaruh variabel independen semakin besar dalam menjelaskan variabel dependen, namun apabila $\mathrm{R}^{2}$ mendekati 0 , maka pengaruh variabel independen semakin kecil dalam menjelaskan variabel dependen.

Berdasarkan tabel diketahui bahwa nilai Adjusted $\mathrm{R}^{2}$ adalah 0,080894 yang menjelaskan bahwa variabel independent ERM mempunyai pengaruh terhadap variabel dependen kompensasi bonus sebesar 8\%, sedangkan 92\% lainnya dijelaskan oleh faktor lain di luar variabel independen dalam penelitian ini.

\section{Uji Signifikansi Parsial}

Uji ini dilakukan untuk mengetahui apakah variabel independen mempunyai pengaruh

JAA terhadap variabel dependen secara parsial. Penjelasan hasil Uji T berdasarkan tabel sebagai

\section{1 berikut:}

Berdasarkan tabel diperoleh nilai probabilitas t-statistic variabel ERM sebesar 0,0568 dengan menggunakan model grover dalam pengukurannya. Dapat disimpulkan bahwa nilai 
probabilitas t-statistic $0,0568<0,1$ maka $\mathrm{H} 1$ diterima. Dengan demikian, variabel independen dengan data yang digunakan berpengaruh secara signifikan terhadap variabel dependen kompensasi bonus di angka 0,1.

Hasil penelitian menunjukkan bahwa praktek earning management pada perusahaan sampel yaitu badan usaha dan unit usaha syariah banyak dilakukan dengan cara income maximization sebanyak 50\% atau sebanyak 17 perusahaan dan melakukan income minimalization sebanyak 50\% atau sebanyak 17 perusahaan. Artinya ketika perusahaan merasa labanya terlalu tinggi, maka manajemen akan menurunkan labanya dan ketika merasa labanya terlalu kecil atau mengalami kerugian manajemen akan menaikkan labanya.

\section{Pengaruh Praktek Earning Management Terhadap Kompensasi}

Berdasarkan hasil pengujian data statistik dapat diketahui bahwa praktek earning management berpengaruh terhadap kompensasi bonus. Nilai tersebut dapat membuktikan bahwa H1 diterima, yang berarti praktek earning management berpengaruh secara signifikan terhadap kompensasi bonus.

Hasil penelitian ini sejalan dengan hasil penelitian tentang earning management terhadap kompensasi bonus adalah Guidry et.al (1999), Elfira (2014) dan Pujiningsih (2011), dalam penelitiannya menunjukkan bahwa ada pengaruh yang signifikan positif antara earning management terhadap kompensasi bonus.

Hasil penelitian ini sejalan dengan teori keagenan (Agency Theory) yang mengimplikasikan adanya asimetri informasi antara pemilik perusahaan (stakeholder) dan manajer sebagai agen. Adanya asimetri informasi menyebabkan manajemen menggunakan informasi yang diketahuinya untuk menyusun laporan keuangan sesuai dengan kepentingan dirinya yaitu meningkatkan kemakmurannya (Jensen dan Meckling 1976). Manajer melakukan perubahan metode akuntansi (earning management) dalam rangka meningkatkan laba, peningkatan laba menyebabkan tingkat kinerja perusahaan semakin tinggi dan kompensasi bonus yang diberikan kepada manajemen semakin tinggi.

\section{SIMPULAN}

Hasil penelitian menunjukkan ada pengaruh yang signifikan antara earning management dengan kompensasi bonus. Earning management perusahaan cenderung tinggi. Nilai yang tinggi juga terlihat pada kompensasi bonus perusahaan. Hal ini menunjukkan bahwa manajemen melakukan earning management dalam rangka memperoleh kompensasi bonus. Adanya earning management diharapkan dapat meningkatkan laba. Selanjutnya, peningkatan laba dapat menyebabkan tingkat kinerja perusahaan semakin tinggi dan kompensasi bonus yang diberikan kepada manajemen semakin tinggi pula.

Pada penelitian ini masih ada keterbatasan yang menghambat selama penelitian dilakukan, yaitu jumlah sampel yang masih terlalu sedikit, jumlah variabel yang digunakan hanya satu, dan jumlah data terlalu sedikit dengan menggunakan 1 tahun periode pengamatan. Bagi peneliti selanjutnya dapat menambahkan sampel dengan banyak perusahaan dengan banyak sektor, menambahkan variable lain dalam penelitianyang dipandang terkait dan mempengaruhi earning management. Peneliti selanjutnya dapat menambahkan periode pengambilan data. 


\section{DAFTAR PUSTAKA}

117 Aprina, D.N. dan Khairunnisa. 2015. "Pengaruh ukuran perusahaan, profitabilitas, dan kompensasi bonus terhadap manajemen laba". e-Proceeding of Management : Vol.2, No.3 Desember 2015 Page 3251.

Badruzaman, N. (2010). Earning management.

Baltagi, B. (2008). Econometric analysis of panel data. John Wiley \& Sons.

Belkaoui, A. R. (2008). Teori Akuntansi jilid 1, Edisi Kelima.

Elfira, A. (2014). Pengaruh Kompensasi Bonus Dan Leverage Terhadap Manajemen Laba (Studi Empiris Pada Perusahaan Manufaktur yang Terdaftar di Bursa Efek Indonesia Tahun 2009-2012). Jurnal Akuntansi, 2(2).

Guidry, F., Leone, A. J., \& Rock, S. (1999). Earnings-based bonus plans and earnings management by business-unit managers. Journal of accounting and economics, 26(1-3), 113142.

Gurajati, D. (2006). Dasar-dasar Ekonometrika Ed ke-3. Erlangga. Jakarta.

Jensen, M. (1976). C. dan William, H. Meckling,". Theory of the Firm: Managerial Behavior, Agency Cost and Ownership.

Kuncoro, M. (2003). Metode riset untuk bisnis dan ekonomi. Jakarta: Erlangga, 52.

Pujiningsih, A. I. (2011). Pengaruh Struktur Kepemilikan. Ukuran Perusahaan, Praktik Corporate Governence dan Kompensasi Bonus Terbadap Manajemen Laba.

Retnadi, D. (2008). Kredit Usaha Rakyat (KUR), Harapan dan Tantangan. Economic Review, 212.

Richardson, V. J. (1998). Information Asymmetry and Earnings Management: Some Evidence. http. ssrn. com.

Schipper, K. (1989). Earnings management. Accounting horizons, 3(4), 91.

Scott, W. R. (2012). Financial Accounting Theory 6th edition'. NY: Pearson Prentice Hall.

Setiawati, L., \& Na'im, A. (2000). Manajemen laba. Journal of Indonesian Economy and Business, 15(4), 424-441.

Shen, C. H., \& Chih, H. L. (2005). Investor protection, prospect theory, and earnings management: An international comparison of the banking industry. Journal of Banking \& Finance, 29(10), 2675-2697.

Subramanyam, K. R., \& Wild, J. J. (2010). Analisis laporan keuangan. Jakarta: Salemba Empat. 